\title{
Web-Based Eligibility Quizzes to Verify Opioid Use and County Residence Among Rural Young Adults: Eligibility Screening Results from a Feasibility Study
}

\author{
April M Ballard $^{1,2}$, MPH; Hannah LF Cooper ${ }^{3}$, SCD; April M Young ${ }^{1,4}$, MPH, PhD \\ ${ }^{1}$ Department of Epidemiology, University of Kentucky, Lexington, KY, United States \\ ${ }^{2}$ Department of Environmental Health, Emory University Rollins School of Public Health, Atlanta, GA, United States \\ ${ }^{3}$ Department of Behavioral Sciences and Health Education, Emory University Rollins School of Public Health, Atlanta, GA, United States \\ ${ }^{4}$ Center on Drug and Alcohol Research, University of Kentucky, Lexington, KY, United States
}

Corresponding Author:

April M Young, MPH, PhD

Center on Drug and Alcohol Research

University of Kentucky

845 Angliana Avenue

Lexington, KY, 40508

United States

Phone: 18592182090

Email: april.young@uky.edu

\section{Abstract}

Background: Web-based methods can be used to collect data from hidden populations, including people who use drugs (PWUD). These methods might be especially advantageous among PWUD in rural areas, where transportation barriers are prevalent, stigma may heighten concerns about confidentiality, and internet access is improving. However, Web-based research with PWUD can be challenging, especially in verifying eligibility. Administering quizzes to verify residential and substance use eligibility could prove valuable in online research among PWUD, yet the utility of this approach is currently unknown.

Objective: This study describes the implementation of online eligibility quizzes about the local community to verify residence in the target study area along with drug dose, appearance, and price to verify opioid misuse.

Methods: To be eligible, individuals had to live in 1 of 5 eastern Kentucky counties, report using opioids to get high in the past 30 days, and be 18 to 35 years old. Participants recruited from August 2017 to July 2018 were asked questions about their opioid use followed by a quiz about drug dose, appearance, and price to verify substance use eligibility. Residential eligibility was verified with 5-question quizzes assessing knowledge of the county where they reported living. Questions tested knowledge about towns, festivals, and landmarks; local school mascots and colors; and presence of certain retail stores, restaurants, and facilities (eg, jails). A subsample that reported using opioids in the past 24 hours was randomly selected to complete urine drug testing (UDT). Nonparametric tests were performed to explore differences across demographic subgroups.

Results: Of the 410 entries assessed for eligibility, 39.3\% (161/410) were ineligible as they reported no substance use, being outside the age range, or living outside the study area. Of the remaining 249 who met the eligibility criteria based on age, residency, and opioid misuse, 94.0\% (234/249) passed the eligibility quizzes. Among those who passed the heroin quiz, 99.4\% (167/168) recognized the image of powdered heroin, 94.6\% (159/168) answered the cap size (ie, the purchase unit) question correctly, and $97.0 \%$ (163/168) answered the street price question correctly. Among those who passed the drug quiz for prescription opioids, $95 \%(36 / 38)$ answered the dose question correctly, and $82 \%(31 / 38)$ selected the correct image. In a random sample of participants who completed UDT within 3 days of their online screening, 74\% (25/34) tested positive for an opioid.

Conclusions: This study demonstrated the utility of using online eligibility screening quizzes to verify opioid misuse and residence. Participants accurately recognized heroin and prescription opioid doses, prices, and images and correctly answered questions about features of their county. Online quizzes to screen and enroll PWUD hold promise for future research as an alternative to more time- and resource-intensive approaches that could offset the advantages of Web-based methods.

(JMIR Res Protoc 2019;8(6):e12984) doi: 10.2196/12984 


\section{KEYWORDS}

Web-based methods; eligibility determination; rural health; substance-related disorders; opioid use; surveys and questionnaires; internet; confidentiality; sampling methods; recruitment

\section{Introduction}

\section{Background}

Studies have shown that Web-based methods can successfully be used to collect data from hidden populations, including men who have sex with men (MSM), people with sexually transmitted infections, and people who use drugs (PWUD) [1-9]. Web-based data collection can decrease barriers to study participation by allowing individuals to complete surveys from any location and by providing participants with a heightened sense of anonymity [10-14]. These methods may be particularly pertinent for research among PWUD because of concerns around legality and stigma of the behaviors they are reporting. Furthermore, the importance of innovations in substance use research is heightened by the increase in substance use and related harms such as overdose mortality in several countries including the United States, Australia, and Europe $[15,16]$.

Rural areas such as central Appalachia have a longstanding and continued problem with prescription opioid misuse and drug-related harms [17]. A steady increase in substance use has occurred over the past 2 decades, with abuse rates exceeding national averages [17]. Methodological innovations in research among rural US populations have, therefore, become increasingly important because of the disproportionate burden of opioid use and related harms (ie, hepatitis C and overdose) affecting rural young adults [17-23]. Furthermore, with $78 \%$ of rural adult Americans reporting use of the internet [24], the methodological advantages of Web-based data collection and recruitment might be especially advantageous for research among hard-to-reach populations in rural settings, where transportation barriers are prevalent and fear of breaches to confidentiality may be heightened because of stigma $[25,26]$. However, no studies to our knowledge have developed and piloted Web-based methods for data collection among rural PWUD, though a number of studies have used Web-based methods to recruit and collect data from PWUD [1,3,9,27-31] in urban settings.

Regardless of rurality, verifying eligibility criteria for studies related to recent substance use with PWUD and residence in a targeted geographic area can be challenging. Web-based methods can further compound these challenges. Substance use self-report can be employed for eligibility screening; however, validation studies using biologic techniques have shown a range of accuracy and under-reporting, with frequency and magnitude depending on drug class and socioecological factors [32,33]. Many in-person studies of PWUD use urine drug testing (UDT), saliva testing, or visual inspection for injection stigmata to verify eligibility [34-42]. These methods, of course, are not possible during online screenings, and using UDT or in-person/virtual consultation to confirm eligibility in Web-based studies would be time- and resource-intensive and could offset the advantages of online research.
Similarly, methods to recruit participants from specific geographic areas and verify residence in those areas can be difficult to implement. Even if study advertisements are targeted (ie, via local outreach and posting local flyers), once a survey link is revealed online and/or the link is shared with peers, people who live outside the target area can access the link. Many online survey platforms have the capacity to record geolocation based on user internet protocol (IP) address and allow researchers to restrict access to online surveys based on geolocation [43-45]. However, geolocation linked to IP address can be inaccurate because when a device is connected to a virtual private network or network address translation, only an external IP address is displayed, causing all devices to have identical IP addresses and geolocation. In addition, smartphones can display multiple different IP addresses within minutes because of network proxies within the carrier's network, resulting in inaccurate geolocation based on IP addresses [46-48]. Recent research among MSM in Kentucky revealed that a substantial proportion of entries with ineligible geolocations based on IP addresses belonged to verified eligible participants [49].

An alternative to in-person UDT and/or visual inspection of participants to verify substance use and IP address geolocation to verify residential location is assessing knowledge about drug use and the target study area. Previous studies have used trained interviewers to assess prospective participants' knowledge about the preparation of drugs for injection, administration of injections, and the size and color of needles and syringes, in addition to visual inspection for injection stigmata [42,50]. Other studies that include PWUD through noninjection routes have used interviewer-administered questionnaires to assess knowledge of street terminology, major formula doses (eg, milligram), and pill images [41,51]. To our knowledge, research that verifies residential eligibility through the assessment of knowledge about the target study area has not been conducted. However, assessing knowledge of local community features such as the names of nearby cities and towns, local businesses, and physical landmarks, in addition to in-person or targeted recruitment strategies (ie, direct marketing, respondent-driven sampling, and venue-based sampling) could be useful in enrollment of participants from a specified geographic area. Thus, substance use and local community quizzes could prove valuable in Web-based survey research among PWUD and in research targeting specific geographic areas.

\section{Objectives}

The aim of this study was to explore the utility of using an online survey to screen and enroll young adult PWUD from rural Kentucky into an online survey about substance misuse and related risk behaviors. This study describes the implementation of an online eligibility screening quiz about the local community to verify residence in the target study area along with drug dose, appearance, and price to verify substance use. 


\section{Methods}

\section{Overview}

Young adults who use opioids were recruited from August 2017 to July 2018 from 5 counties in rural Appalachian Kentucky to participate in an online survey, programmed in SurveyGizmo [42]. The survey contained questions about participants' substance use, sexual and drug-related risk behaviors, and risk environments. Eligibility criteria included being 18 to 35 years old, living in the 5-county study area, and using opioids to get high in the past 30 days. Opioids included prescription pain pills, heroin, buprenorphine, methadone, and synthetic opioids. The study was funded to focus on individuals aged 18 to 35 years because of the disproportionate burden of opioid use and related harms (ie, hepatitis $\mathrm{C}$ and overdose) impacting young adults in rural settings [21-24,28,52].

Participants were recruited using both targeted and Web-based peer referral methods. Targeted outreach included distributing flyers at local businesses and organizations where young PWUD may be present (eg, tobacco shops, laundromats, gas stations, and social service offices), referrals from staff from another study on PWUD in the target area, and hosting community cookouts that advertised the study. Those who were eligible and completed the survey also had the option to refer peers through emailed or text messaged electronic peer referral coupons. Participants received US $\$ 10$ for up to 3 eligible referrals who completed the survey. Study flyers and recruitment coupons had a URL for a study website hosted by WordPress [53], which had the link to the SurveyGizmo screening survey. The website also provided information for completing the screening assessment, informed consent, and survey. Flyers' text included a university and study $\log 0$ and stated that participants who lived in the 5-county study area were needed for a study on rural health. The flyers did not disclose that the study was focused on drug use.

Informed consent was self-administered for both the online screening and the survey. The consent also informed participants that UDTs would be administered to a random subsample of participants. To demonstrate comprehension, participants were required to answer 4 questions correctly at the end of the consent form that covered the content of the informed consent. After informed consent, participants were asked how they would like to be compensated. Options included cash, money wire, gift card, or an e-gift card of US \$30. UDT compensation was US $\$ 25$ and was given in-person at the time of urine specimen collection.

Before beginning the full online survey, eligibility was assessed using the date of birth to capture age and quizzes that examined knowledge about opioids and the local community to verify substance use and residence, respectively. Before initiating recruitment, we conducted pilot tests of these quizzes with young adult PWUD living in the study area. Information gathered was used to make adjustments to the quizzes to maximize utility and clarity before participant enrollment.

\section{Quiz to Verify Substance Use Eligibility}

To verify substance use, people were asked questions about their use, followed by a quiz. First, people were asked to select all substances they had used to get high in the past 30 days from a list containing several opioids (eg, heroin, synthetic opioids, buprenorphine, methadone, and prescription opioids), nonopioids (eg, prescription sedatives or tranquilizers, cocaine, crack, methamphetamine, gabapentin, bath salts, and hallucinogens), and other, followed by a write-in response. Participants also had the option to select none of these. Those who had not used any substance to get high in the past 30 days were not quizzed and skipped the remaining substance use items.

People who reported using prescription opioids to get high were asked to specify which prescription opioid(s) they used using a checklist. People who reported using any opioid were then asked to specify which opioid they had used most often to get high in the past 30 days. Those who reported and specified which prescription opioid they had used were given the option to select that particular drug.

The drug quiz queried the opioid they reported using most often in the past 30 days. If they had used other nonopioids to get high, in addition to opioids, the most often follow-up question only listed opioids to ensure they were quizzed on a drug that related to eligibility criteria. Drug-specific opioid and nonopioid quizzes are described below.

\section{Heroin Quiz}

People who reported heroin as their most frequently used opioid in the past 30 days were administered a similar, 4-question quiz. First, they were asked what the most common size for a cap, or one hit, of heroin was in their county with the following response options: one-tenth of a gram (correct), one gram, five grams, and 20 grams. People were then asked how much 1 cap or hit of heroin cost in their town, with the following response options: US \$0-\$10, \$10-\$50 (correct), \$50-75, and more than $\$ 75$. Local law enforcement experts who arrange undercover drug purchases and local PWUD were consulted for information on cap size (1/10th of a gram or $100 \mathrm{mg}$ ) and heroin price (US $\$ 20$ to $\$ 40$ per cap).

Finally, people were asked to identify which photograph looked most like the heroin they buy in their county and were given 10 images as options, with 5 showing different types of powder heroin ranging from white to dark brown and 5 showing images that had textures and/or colors that would obviously not be heroin to a heroin user. People were required to get either the most common size or the cost for 1 cap of heroin correct to pass the heroin quiz. Image recognition was not included in the heroin quiz score, as it is possible that some people may only see heroin after it has been dissolved and heated for injection.

\section{Prescription Opioid Quiz}

For nonmedical use of prescription opioids, buprenorphine, and methadone, quizzes involved multiple-choice questions about dose (ie, choosing the dose from a list of real and fake milligrams options) and appearance (ie, recognizing an image from a set of correct and incorrect images). Because most prescription opioid pills, lozenges, films, or tablets are made in 
multiple doses and have different appearances depending on dose, formulation, and manufacturer, the quiz's branching and skip patterns had to account for each drug/dose combination. Questions had a varying number of response options depending on the number of actual doses and images that were possible, such that $50 \%$ of options were correct and $50 \%$ were incorrect. For example, as shown in Figure 1, Roxicodone is manufactured as 5, 15, and $30 \mathrm{mg}$ pills; therefore, the dose question had 6 response options so that $50 \%$ of options were correct and $50 \%$ were incorrect. Similarly, sets of response options for questions on Roxicodone images for each dose contained $50 \%$ correct responses. Incorrect dosage selection branched to an image question that provided images of all doses so that even if participants selected the incorrect dose, they still had the opportunity to identify the correct image.

People were also asked about the street price in an open-ended question. They were instructed to leave the answer blank if they did not know it. Because the study team was unable to gather information on street price for every possible prescription opioid, milligram, formulation, and manufacturer, this question was not included in the quiz score. People were only required to get either dose or image correct to pass the prescription opioid quiz.

Figure 1. Example sequence of questions from the online screening eligibility process for prescription opioid quiz for Roxicodone.

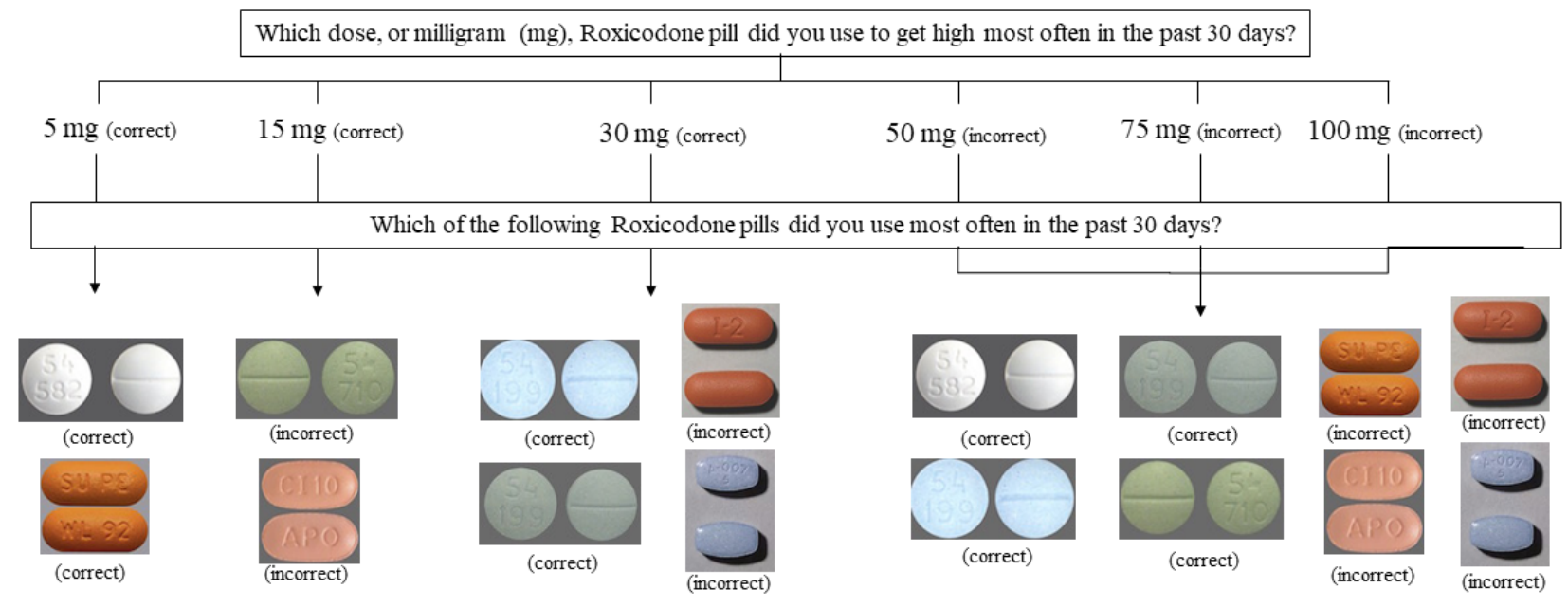

\section{Synthetic Opioid Quiz}

Because of the recent emergence and rapidly evolving nature of the synthetic opioid market, we could not program a scorable quiz for synthetic opioids. If a person reported using synthetic opioids, they were asked where people normally get synthetic opioids (online, gas stations, drug paraphernalia stores, or other), what type of substance synthetic opioids were (pills, powder, liquid, and other), and price for 1 dose. The answers were not scored, and people who reported synthetic opioids as their most commonly used drug were automatically deemed eligible for the survey if they completed the screener and were otherwise eligible.

\section{Nonopioid Quiz}

People who did not report opioid use received a brief quiz because if quizzes were only given to those who initially reported opioid use, it could serve as a clue to people about what type of drug use would qualify them for the study. Therefore, to avoid unmasking eligibility criteria, people who had not used an opioid (ie, methamphetamine, cocaine, bath salts, or hallucinogens) were administered a 3-question quiz on the nonopioid drug they reported using in the past 30 days. The quiz asked about the drug's color and texture (ie, pill, liquid, powder, rocks, or other), as well as an open-ended item on dose or common size for a bag of the drug. The nonopioid quizzes were not programmed to be scored.

\section{Quiz to Verify Residential Eligibility}

To verify residence in the 5-county area, people were asked which state and county they had slept in most often in the past 6 months and then were administered a 5-question quiz assessing their knowledge of that county. Quiz items for study area counties were drawn at random from a 10-question bank developed specifically for that county. A question bank was used so that if a person tried to coach another respondent as they took it simultaneously or at a later date or tried to take the screening survey multiple times until they passed, it would be harder to share and/or learn the answers.

Quiz items contained yes/no and multiple-choice questions with the latter having 4 or 5 response options. For each eligible county, county-specific quiz items queried topics that were known widely within the county but most likely were unknown to people who did not live in the county. A total of 6 of the 10 quiz item topics were the same across counties; however, the remaining 4 items in the bank varied across eligible counties based on what features were applicable and salient (see Multimedia Appendix 1). Questions and topics were chosen based on suggestions from community members who attended local recruitment events and from local community partners. People were required to get 3 out of 5 questions correct to pass the county quiz.

A generic county quiz was administered when individuals reported living outside the 5-county study area to help mask which counties were eligible. The generic county quiz was pulled from a 10-question bank that had similar content 
presented in Multimedia Appendix 1. Responses to these items were not scored, as correct answers for all possible noneligible counties were unknown and simply stating that they lived outside the 5-county area disqualified persons from the study.

\section{Urine Drug Testing}

A subsample $(n=34)$ of survey participants who reported using opioids in the 24 hours before completing the screening were randomly selected to complete a 13-Panel iCup Drug Test within 3 days of the survey based on drug detection windows. The survey tool was programmed to randomly select participants for UDT if they completed the survey and reported using opioids in the past 24 hours. The iCup test is an extensive UDT for 13 different drugs including opiates (heroin and morphine), buprenorphine (Suboxone, Subutex, and Temgesic), methadone (Dolophine, Methadose, and Physetone), oxycodone (Percocet, Percodan, OxyContin, and Tylox), and propoxyphene (Darvocet and Darvon), as well as various stimulants, sedatives, and other drugs [54]. According to the manufacturer, most drugs appear in urine 2 to 5 hours after use, and drug detection windows vary based on several factors including frequency of use, route of administration, body mass, and age. Participants who were randomized to receive a UDT were contacted by the study staff to schedule an appointment at a local venue to obtain the urine specimen.

\section{Analysis}

Descriptive statistics were used to describe results of the online eligibility screening algorithm and quizzes and to compare UDT results with self-reported opioid use. Nonparametric tests (eg, Kruskal-Wallis test and Spearman rank-order correlation) were performed because of non-normal distribution of outcome variables to explore associations across subgroups using SPSS Statistics version 25.0 (SPSS Inc).

\section{Ethics}

All study procedures were approved by the University of Kentucky Institutional Review Board, and data were protected by a Federal Certificate of Confidentiality. To ensure anonymity, IP address and geolocation of the device used when completing the survey were not collected. All data were password-protected and stored on a secure server.

\section{Results}

\section{Overview}

Figure 2 describes the results of the eligibility screening. In total, there were 528 entries in the online eligibility screening survey, $22.3 \%$ (118/528) of which were incomplete (see Figure 2 ). Among the complete entries, the median time required to complete the screening was 6.14 min (interquartile range: 3.65-8.82 $\mathrm{min}$ ). Of the 410 complete entries, $57.1 \%$ (234/410) were deemed eligible. Over half $(229 / 410,55.9 \%)$ were male, and the average age was 30 years (SD 11 years). Data integrity (ie, fraud detection) and final survey sample characteristics of eligible participants are published elsewhere [53]. Most $(116 / 176,65.9 \%)$ of the ineligible entries were due to not reporting any recent opioid use, followed by $41 \%$ (72/176) who reported being outside the eligible age range (18-35 years) and $13.1 \%$ (23/176) reporting living outside the study area. Only $6.8 \%(12 / 176)$ of ineligible entries were classified as ineligible because of failing the county quiz $(n=5)$ and/or drug quiz $(n=7)$. It should be noted that ineligibility data presented in Figure 2 are not exclusive; people may have been ineligible based on multiple criteria. 
Figure 2. Outcomes of the online screening process from the online study of young people who use opioids.

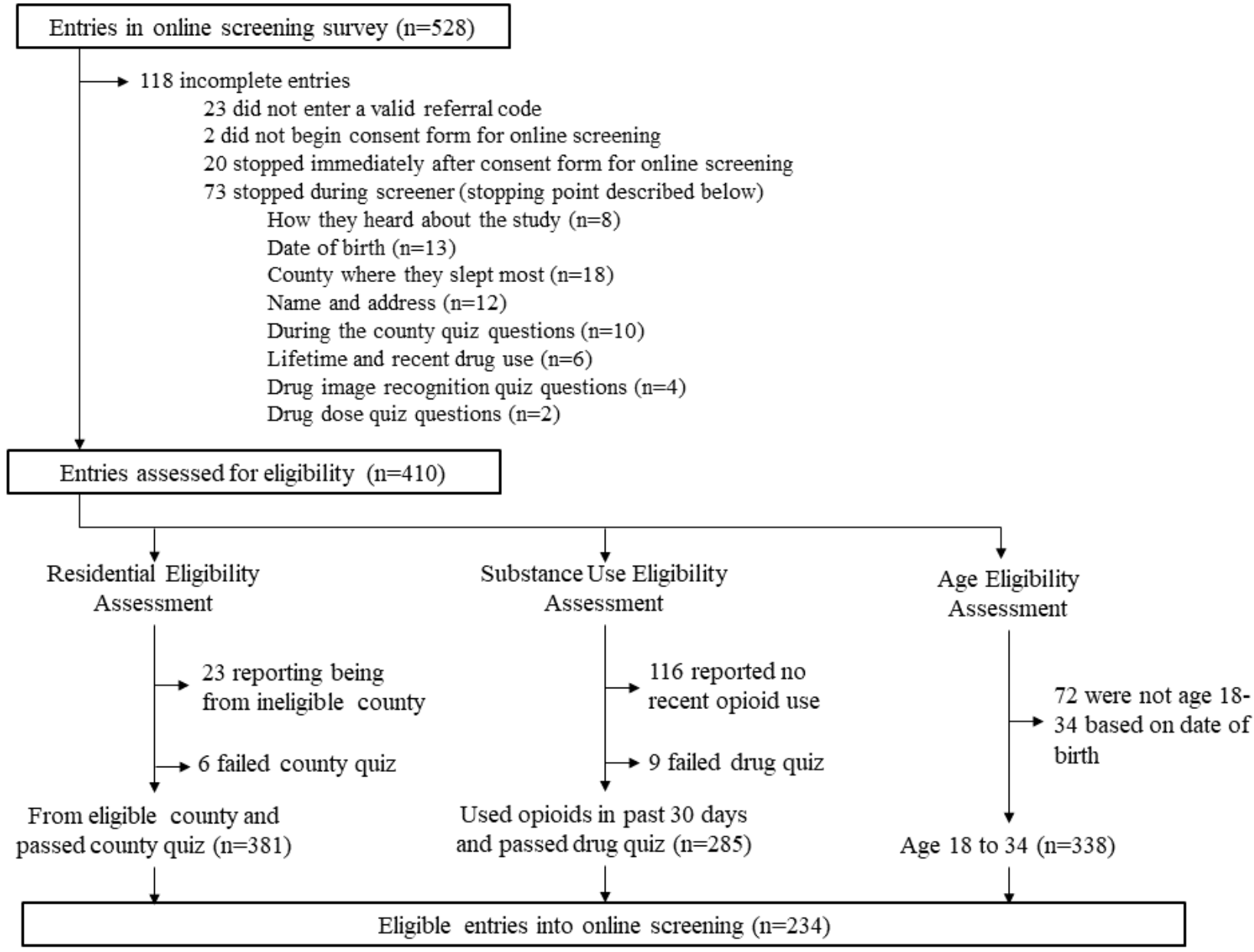

\section{Drug Quiz Results}

In total, only 4 people failed the drug quiz for heroin, as a result of answering both the cap size and street price question incorrectly. Among the 168 people who passed the drug quiz for heroin, $167(99.4 \%)$ recognized the image of powdered heroin, $159(94.6 \%)$ answered the cap size question correctly, and $163(97.0 \%)$ answered the street price question correctly. In total, $91.7 \%(154 / 168)$ answered the cap size and street price questions correctly. Because of the low variance on the quiz scores, we lacked the statistical power to examine variables associated with performance on the heroin quiz.

The most common prescription opioid that participants had used most frequently in the past 30 days and were, therefore, quizzed on was Percocet $(n=18)$, followed by Norco $(n=5)$, fentanyl $(n=4)$, Roxicodone and Lortab (each with $n=3)$, Tramadol and Tylox (each with $n=2$ ), and Opana and OxyContin (each with $\mathrm{n}=1$ ). A total of 2 participants failed the drug quiz for prescription opioids, 1 for Percocet and 1 for Tylox. Among the 38 people who passed the drug quiz for a prescription opioid, $36(95 \%)$ answered the dose question correctly, and $31(82 \%)$ selected the correct image. Of those who selected incorrect prescription opioid images, 1 was for Norco and 6 were for Percocet. The 2 incorrect dose responses were also for the Percocet drug quiz.
In total, 74 people reported buprenorphine as their most frequently used drug in the past 30 days, with most ( $n=66$ ) using buprenorphine pills. Among those quizzed about buprenorphine pills, 3 answered the dose and image questions incorrectly and failed the drug quiz. Of those who passed the drug quiz, 95\% (60/63) answered the dose question and 92\% (58/63) answered the image question correctly. In total, 84\% (53/63) answered the dose and image questions correctly. Among those quizzed about buprenorphine strips, all passed the drug quiz, with $89 \%$ (8/9) answering both dose and image questions correctly.

A total of 4 people were quizzed on methadone, 1 on liquid methadone, and 3 on pills. No participant failed the methadone drug quiz. Only 1 person answered a methadone quiz question incorrectly, which was the methadone pill dose question.

\section{County Quiz Results}

A Kruskal-Wallis test was conducted to examine differences in the quiz score across the 5 counties in the study area. No statistically significant differences in quiz scores were found across the 5 counties $\left(\chi_{4}^{2}=6.9, P=.14\right)$. Of the 6 parallel questions that were asked for every county in the study area (see Multimedia Appendix 1), the item querying smallest communities in the county was answered incorrectly most frequently, followed by if there was a jail or prison in the county, the local physical landmark specific to the county, and if there was a Walmart in the county. Among the 381 people who passed the county quiz for an eligible county, the average score was 
4.9 (range 0-5) and most (91.1\%) answered all 5 questions correctly.

Spearman rank-order correlation was used to investigate whether there was an association between length of residence in the county and county quiz score among those who were eligible and completed the survey. There was no statistically significant association between length of residence in the county and county quiz score $\left(r_{\mathrm{s}}=.03, P=.74\right)$. Of note, length of residence could not be assessed as a correlate to county quiz score among those who failed the county quiz because duration of residence was only collected from those who participated in the study.

\section{Urine Drug Testing Results}

Among the 44 individuals who were randomized to UDT, 34 completed the UDT within 3 days of their survey. Of these,
$74 \%$ (25/34) tested positive for any opioid, including 27\% (9/34) who tested positive for opiates (ie, heroin), 50\% (17/34) who tested positive for buprenorphine, and $3 \%(1 / 34)$ who tested positive for oxycodone (see Table 1). Overall, 64.7\% (22/34) tested positive for any stimulant. In addition, $6 \%(2 / 34)$ tested positive for benzodiazepine and $3 \%$ (1/34) for phencyclidine. Only 2 participants did not test positive for any drug.

Table 2 describes test results based on the opioid they reported (1) using most frequently in the past 30 days and (2) using in the past 24 hours. Slightly more than $50 \%(18 / 34)$ had urinalysis results that matched the opioid they reported using most frequently in the past 24 hours.

Table 1. Comparison of self-reported use of opioids with results of the 13-panel iCup urine drug test completed within 3 days of self-reported use.

\begin{tabular}{lllll}
\hline $\begin{array}{l}\text { Opioid used within past } 24 \\
\text { hours }^{\mathrm{a}}\end{array}$ & $\begin{array}{l}\text { Those with positive UDT } \\
\mathrm{n}(\%)\end{array}$ & $\begin{array}{l}\text { Days since survey completion, } \\
\text { average (range) }\end{array}$ & $\begin{array}{l}\text { UDT detection window, } \\
\text { days [54] }\end{array}$ & $\begin{array}{l}\text { Detection threshold, ng/mL } \\
\text { [54] }\end{array}$ \\
\hline Heroin $\left(\mathrm{n}^{\mathrm{d}}=21\right)$ & $8(38)$ & $0.22(0-1)$ & $2-4$ & 2000 \\
Buprenorphine $\left(\mathrm{n}^{\mathrm{d}}=9\right)$ & $8(89)$ & $0.52(0-3)$ & $2-3$ & 10 \\
Percocet (oxycodone; $\left.\mathrm{n}^{\mathrm{d}}=4\right)$ & $1(25)$ & $0.75(0-1)$ & $2-4$ & 100 \\
\hline
\end{tabular}

${ }^{\text {a }}$ Participants had self-reported the opioid they used most often in the past 30 days and also reported use in the 24 hours before completing the screening. ${ }^{\mathrm{b}}$ UDT: urine drug test.

${ }^{\mathrm{c}}$ Days elapsed between survey completion and UDT completion. Zero means that the screening was performed the same day.

${ }^{\mathrm{d}}$ The number of people who completed the UDT.

Table 2. Urine drug testing results of 13-panel iCup urine drug test completed within 3 days of self-reported use (N=34).

\begin{tabular}{|c|c|c|c|}
\hline Drug & $\begin{array}{l}\text { Positive } \mathrm{UDT}^{\mathrm{a}} \text {, } \\
\mathrm{n}(\%)\end{array}$ & UDT detection window, days [54] & Detection threshold, ng/mL [54] \\
\hline Marijuana & $18(53)$ & $15-30$ & 50 \\
\hline Opioids & $25(74)$ & $-\mathrm{b}$ & - \\
\hline Opiates (heroin, morphine) & $9(27)$ & $2-4$ & 2000 \\
\hline Methadone & $0(0)$ & $3-5$ & 300 \\
\hline Oxycodone & $1(3)$ & $2-4$ & 100 \\
\hline Propoxyphene & $0(0)$ & $1-2$ & 300 \\
\hline Buprenorphine & $17(50)$ & $2-3$ & 10 \\
\hline Stimulants & $22(65)$ & - & - \\
\hline Methamphetamine & $21(62)$ & $3-5$ & 1000 \\
\hline Amphetamine & $21(62)$ & $2-4$ & 1000 \\
\hline Cocaine & $3(9)$ & $2-4$ & 300 \\
\hline Benzodiazepines & $2(6)$ & $3-7$ & 300 \\
\hline Phencyclidine & $1(3)$ & $7-14$ & 25 \\
\hline Barbiturates & $0(0)$ & $4-7$ & 300 \\
\hline Any drug (excluding marijuana and tricyclic antidepressant) & $30(83)$ & - & - \\
\hline
\end{tabular}

${ }^{\mathrm{a} U D T}$ : urine drug test.

${ }^{\mathrm{b}}$ Not applicable. 


\section{Discussion}

\section{Principal Findings}

Web-based recruitment and data collection can be leveraged for research among hidden populations. However, tools for verifying behavioral and geographic eligibility criteria, such as recent substance use and residence, in Web-based research are lacking. This study demonstrated the utility of using online eligibility screening quizzes to verify substance use and residence in an online survey of young adult PWUD from rural Kentucky. In a random sample of participants who completed UDT within 3 days of their online screening, $73.5 \%$ (25/34) tested positive for an opioid, with drug detection windows ranging from 1 to 5 days. Only 2 did not test positive for any drug. In addition, most of those who reported recent opioid use $(285 / 294,97.0 \%)$ and living in the 5-county study area (381/387, $98.4 \%$ ) were able to pass the respective quizzes.

Quizzes to verify substance use queried drug dose, price, and image recognition. People were able to offer accurate answers to these questions across opioid types. For example, among those who reported heroin as their most frequently used drug in the past 30 days, most $(154 / 168,91.7 \%)$ answered the cap size and street price questions correctly, and every participant except 1 was able to successfully recognize an image of powdered heroin. Most participants who passed a prescription opioid drug quiz were able to correctly answer dose and image questions $(28 / 39,71.8 \%)$. Of note, Percocet was the most common prescription opioid that participants reported using most frequently in the past 30 days and had a greater proportion of incorrect pill image and dose responses. During the study, researchers anecdotally discovered that the street name for Roxicodone (eg, Perc 30s) may have led people who were using Roxicodone to incorrectly select Percocet and subsequently be unable to correctly identify dose and pill images. Formula doses, pill images, and drug street names may vary across settings and should be considered when developing similar tools. PWUD within the setting may be a vital resource to ensure proper tool development. In addition, to avoid unmasking the eligibility criteria in studies focused on specific drug classes (such as opioids as done in this study), it is important to administer quiz questions for all drug classes.

People also performed well on quizzes that were used to verify their residence in the 5-county study area. Of those who reported being from an eligible county, $1.6 \%$ (6/387)failed the eligibility quiz. Questions that had the highest proportion of correct answers were those about businesses or facilities in the county (ie, whether there was a particular grocery store such as Kroger, Walmart, or local chains in their county, a particular pizza restaurant in their county). Questions that appeared to be most difficult for participants were multiple-choice items that asked them to identify the county's largest town/city and which among the 5 lists of small communities was located in their county. Furthermore, depending on the length of a study and turnover in communities, changes in local businesses and facilities may need to be considered when utilizing community-specific quizzes.
Community member input and pilot testing were essential to the development of the county quizzes. In this study, community partners who worked in local public health and social service agencies helped develop sets of 10 questions for each of the 5 eligible counties; quizzes were then piloted with local PWUD. Initially, quizzes contained questions on high school mascots and colors, but feedback from local PWUD revealed that those who moved to the area more recently may not know information about local schools, so the questions were revised. Pilot-testing results highlight the need to engage community members in the development of quizzes and to pilot-test quizzes in the target sample. These findings may also reveal the need for future studies to collect data on duration of residence in the screening instrument and to potentially vary the threshold for passing based on the length of residence. In addition, to minimize inapposite participation that could result from advertising online or, more broadly, where geographic ineligibility could be more problematic, study advertising should be targeted. In this study, community cookouts, flyers, and outreach by local study staff were used to advertise the study, which may have resulted in the low percentage $(23 / 410,5.6 \%)$ of screening survey participants who reported being from a county outside the eligible study area.

\section{Limitations}

Although using Web-based methods to screen and enroll young adult PWUD was successful in this study, there were limitations. Quizzes are limited in their ability to distinguish people who have ever used substances from those who have used recently, given that drug prices, doses, and appearances may not vary drastically over time. In addition, creating quizzes for nonprescription opioids such as heroin and synthetic opioids is more difficult because of lack of manufactured doses and potential inconsistencies in appearance. Quizzes for these drugs may, therefore, need to be more vague and consequently easier to pass. This study's small strata-specific sample sizes (ie, by drug and by county) limited its ability to detect correlates to quiz performance and precluded a more rigorous statistical comparison of quiz results with urine drug screen outcomes. Future research could examine differences in quiz performance by drug type and examine other correlates to quiz performance. Other analytic approaches such as factor analysis were not employed in this study because each quiz was slightly different across counties based on county features and for each drug based on dosages, pill manufacturers, and appearances. In future research involving a larger, more homogenous sample (ie, in 1 interested in use of a single drug) or more limited geographic area, psychometric properties of quizzes could be evaluated.

Narrow UDT detection windows limited our ability to compare test results with self-reported past 30-day substance use [54]. Future research could utilize hair, saliva, or blood tests that have longer detection windows and better capture eligibility recall periods [37]. Finally, technological issues could also create a barrier to participation or lead to inaccurate ineligibility. Informal conversations with participants revealed that some had difficulty entering their date of birth because of the appearance of the question on some smartphone devices; others experienced problems with loading image questions because of internet speed and connectivity. Of note, $48.3 \%(72 / 151)$ of 
participants reported completing the survey on a smartphone, $28.9 \%(43 / 151)$ on a computer, $10.7 \%(16 / 151)$ on a tablet, and $12.1 \%(18 / 151)$ on some other device [55].

\section{Clinical and Research Applicability}

Innovative screening approaches are becoming increasingly important with the rise in Web-based research. Methods that utilize technology are, therefore, necessary both to ensure enrollment of truly eligible participants and to prevent fraudulent participation. Online quizzes to screen and enroll PWUD hold promise for future research as an alternative to more time- and resource-intensive approaches that could offset the advantages of Web-based methods. Online eligibility quizzes could also prove useful for studies that are not Web-based, as they could be used for eligibility screening and thereby reduce burden on staff of screening study participants through interviewer-administered approaches. Furthermore, as technology evolves, new methods for eligibility verification may emerge, particularly in studies where participants are using smartphones. For example, image recognition software could be used to recognize injection stigmata in studies of people who inject drugs or to verify residence in a target community through photographs of landmarks. With advances in drug testing and remote diagnostic confirmation using smartphones through saliva- [56,57], urine- [57,58], and serum-based assays [57], smartphone-based testing also may be integrated into future online studies of PWUD. Geocaching [58] and global positioning system targeting technology such as those used in online gaming and gambling to validate that a patron is within authorized jurisdictional boundaries $[59,60]$ may be used in the future to verify residential eligibility. Although new technologies are promising, until they are seamlessly integrated into survey platforms, strict data security measures are in place, and smartphone ownership is ubiquitous, quizzes to assess eligibility will continue to be an important tool for screening and enrollment of participants into online research.

\section{Acknowledgments}

This study was funded by the National Institute on Drug Abuse (R21 DA042727; principal investigators (PIs): HLFC and AMY). Community partners who provided feedback during the development of the quiz were identified through an ongoing study supported by the National Institute on Drug Abuse, Centers for Disease Control and Prevention (CDC), Substance Abuse and Mental Health Services Administration (SAMHSA), and the Appalachian Regional Commission (ARC; UG3 DA044798; PIs: AMY and HLFC); the content is solely the responsibility of the authors and does not necessarily represent the official views of the National Institutes of Health, CDC, SAMHSA, or ARC. The authors thank community researchers, Mary Beth Lawson, Travis Green, and Cindy Jolly for assistance with survey administration and logistics, as well as the Emory Center for AIDS Research (P30 AI050409; PIs: del Rio, Curran, Hunter), Nicole Luisi, and Danielle Lambert for technical support with survey programming, and Nadya Prood for study support.

\section{Conflicts of Interest}

None declared.

\section{Multimedia Appendix 1}

Quiz questions used to verify residential eligibility in a 5-county study area.

[PDF File (Adobe PDF File), 67KB-Multimedia Appendix 1]

\section{References}

1. Bauermeister JA, Zimmerman MA, Johns MM, Glowacki P, Stoddard S, Volz E. Innovative recruitment using online networks: lessons learned from an online study of alcohol and other drug use utilizing a web-based, respondent-driven sampling (webRDS) strategy. J Stud Alcohol Drugs 2012 Sep;73(5):834-838 [FREE Full text] [Medline: 22846248]

2. Bengtsson L, Lu X, Nguyen QC, Camitz M, Hoang NL, Nguyen TA, et al. Implementation of web-based respondent-driven sampling among men who have sex with men in Vietnam. PLoS One 2012;7(11):e49417 [FREE Full text] [doi:

10.1371/journal.pone.0049417] [Medline: 23152902]

3. Crawford SS. Revisiting the outsiders: innovative recruitment of a marijuana user network via web-based respondent driven sampling. Soc Network 2014;03(01):19-31. [doi: 10.4236/sn.2014.31003]

4. Sanchez T, Smith A, Denson D, Dinenno E, Lansky A. Internet-based methods may reach higher-risk men who have sex with men not reached through venue-based sampling. Open AIDS J 2012;6:83-89 [FREE Full text] [doi: 10.2174/1874613601206010083] [Medline: 23049657]

5. Strömdahl S, Lu X, Bengtsson L, Liljeros F, Thorson A. Implementation of web-based respondent driven sampling among men who have sex with men in Sweden. PLoS One 2015;10(10):e0138599 [FREE Full text] [doi: 10.1371/journal.pone.0138599] [Medline: 26426802]

6. Theunissen K, Hoebe C, Kok G, Crutzen R, Kara-Zaïtri C, de Vries N, et al. A web-based respondent driven sampling pilot targeting young people at risk for chlamydia trachomatis in social and sexual networks with testing: a use evaluation. Int J Environ Res Public Health 2015 Aug 20;12(8):9889-9906 [FREE Full text] [doi: 10.3390/ijerph120809889] [Medline: 26308015] 
7. Wejnert C, Heckathorn D. Web-based network sampling. Sociol Methods Res 2008 Aug;37(1):105-134. [doi: 10.1177/0049124108318333]

8. Miner MH, Bockting WO, Romine RS, Raman S. Conducting Internet research with the transgender population: reaching broad samples and collecting valid data. Soc Sci Comput Rev 2012 May 1;30(2):202-211 [FREE Full text] [doi: 10.1177/0894439311404795] [Medline: 24031157]

9. Wilkerson JM, Shenk JE, Grey JA, Simon Rosser BR, Noor SW. Recruitment strategies of methamphetamine-using men who have sex with men into an online survey. J Subst Use 2015;20(1):33-37 [FREE Full text] [doi: 10.3109/14659891.2013.868936] [Medline: 25642143]

10. Bauermeister J, Pingel E, Zimmerman M, Couper M, Carballo-Diéguez A, Strecher VJ. Data quality in web-based HIV/AIDS research: handling invalid and suspicious data. Field methods 2012 Aug 1;24(3):272-291 [FREE Full text] [doi: 10.1177/1525822X12443097] [Medline: 23180978]

11. Bowen AM, Daniel CM, Williams ML, Baird GL. Identifying multiple submissions in Internet research: preserving data integrity. AIDS Behav 2008 Nov;12(6):964-973 [FREE Full text] [doi: 10.1007/s10461-007-9352-2] [Medline: 18240015]

12. Grey JA, Konstan J, Iantaffi A, Wilkerson JM, Galos D, Rosser BR. An updated protocol to detect invalid entries in an online survey of men who have sex with men (MSM): how do valid and invalid submissions compare? AIDS Behav 2015 Oct;19(10):1928-1937. [doi: 10.1007/s10461-015-1033-y] [Medline: 25805443]

13. Mustanski B. Getting wired: exploiting the internet for the collection of valid sexuality data. J Sex Res 2001 Nov;38(4):292-301. [doi: 10.1080/00224490109552100]

14. Sullivan PS, Grey JA, Simon RB. Emerging technologies for HIV prevention for MSM: what we have learned, and ways forward. J Acquir Immune Defic Syndr 2013 Jun 1;63(Suppl 1):S102-S107 [FREE Full text] [doi: 10.1097/QAI.0b013e3182949e85] [Medline: 23673879]

15. Martins SS, Sampson L, Cerdá M, Galea S. Worldwide prevalence and trends in unintentional drug overdose: a systematic review of the literature. Am J Public Health 2015 Nov;105(11):e29-e49. [doi: 10.2105/AJPH.2015.302843] [Medline: 26451760]

16. Degenhardt L, Stockings E, Patton G, Hall WD, Lynskey M. The increasing global health priority of substance use in young people. Lancet Psychiatr 2016 Mar;3(3):251-264. [doi: 10.1016/S2215-0366(15)00508-8]

17. Moody LN, Satterwhite E, Bickel WK. Substance use in rural central Appalachia: current status and treatment considerations. Rural Ment Health 2017 Apr;41(2):123-135 [FREE Full text] [doi: 10.1037/rmh0000064] [Medline: 29057030]

18. Zibbell J, Iqbal K, Patel R, Suryaprasad A, Sanders KJ, Moore-Moravian L, Centers for Disease ControlPrevention (CDC). Increases in hepatitis $\mathrm{C}$ virus infection related to injection drug use among persons aged $\leq 30$ years - Kentucky, Tennessee, Virginia, and West Virginia, 2006-2012. MMWR Morb Mortal Wkly Rep 2015 May 8;64(17):453-458 [FREE Full text] [Medline: 25950251]

19. Paulozzi LJ. Prescription drug overdoses: a review. J Safety Res 2012 Sep;43(4):283-289. [doi: 10.1016/j.jsr.2012.08.009] [Medline: 23127678]

20. Paulozzi LJ, Xi Y. Recent changes in drug poisoning mortality in the United States by urban-rural status and by drug type. Pharmacoepidemiol Drug Saf 2008 Oct;17(10):997-1005. [doi: 10.1002/pds.1626] [Medline: 18512264]

21. Valdiserri R, Khalsa J, Dan C, Holmberg S, Zibbell J, Holtzman D, et al. Confronting the emerging epidemic of HCV infection among young injection drug users. Am J Public Health 2014 May;104(5):816-821. [doi: 10.2105/AJPH.2013.301812] [Medline: 24625174]

22. Zibbell JE, Hart-Malloy R, Barry J, Fan L, Flanigan C. Risk factors for HCV infection among young adults in rural New York who inject prescription opioid analgesics. Am J Public Health 2014 Nov;104(11):2226-2232. [doi: 10.2105/AJPH.2014.302142] [Medline: 25211717]

23. Van Handel MM, Rose CE, Hallisey EJ, Kolling JL, Zibbell JE, Lewis B, et al. County-level vulnerability assessment for rapid dissemination of HIV or HCV infections among persons who inject drugs, United States. J Acquir Immune Defic Syndr 2016 Dec 1;73(3):323-331 [FREE Full text] [doi: 10.1097/QAI.0000000000001098] [Medline: 27763996]

24. Anderson M. Pew Research Center. About a Quarter of Rural Americans Say Access to High-speed Internet is a Major Problem URL: https://tinyurl.com/y6c6uqcl [accessed 2018-11-24] [WebCite Cache ID 749mUStFa]

25. Draus P, Carlson RG. Down on main street: drugs and the small-town vortex. Health Place 2009 Mar;15(1):247-254 [FREE Full text] [doi: $10.1016 / j$.healthplace.2008.05.004] [Medline: 18614387 ]

26. Draus P, Siegal H, Carlson R, Falck R, Wang J. Cracking the cornfields: recruiting illicit stimulant drug users in rural Ohio. Sociol Q 2016 Dec 2;46(1):165-189. [doi: 10.1111/j.1533-8525.2005.00008.x]

27. Daniulaityte R, Lamy FR, Barratt M, Nahhas RW, Martins SS, Boyer EW, et al. Characterizing marijuana concentrate users: a web-based survey. Drug Alcohol Depend 2017 Dec 1;178:399-407 [FREE Full text] [doi: 10.1016/j.drugalcdep.2017.05.034] [Medline: 28704769]

28. Lopez-Rodriguez JA, Valladolid GR. Web-based alcohol, smoking, and substance involvement screening test results for the General Spanish population: cross-sectional study. J Med Internet Res 2018 Feb 16;20(2):e57 [FREE Full text] [doi: 10.2196/jmir.7121] [Medline: 29453188]

29. Miller PG, Sønderlund AL. Using the internet to research hidden populations of illicit drug users: a review. Addiction 2010 Sep;105(9):1557-1567. [doi: 10.1111/j.1360-0443.2010.02992.x] [Medline: 20626378] 
30. Tait RJ, McKetin R, Kay-Lambkin F, Carron-Arthur B, Bennett A, Bennett K, et al. Six-month outcomes of a web-based intervention for users of amphetamine-type stimulants: randomized controlled trial. J Med Internet Res 2015 Apr 29;17(4):e105 [FREE Full text] [doi: 10.2196/jmir.3778] [Medline: 25925801]

31. Thrash C, Welch-Lazoritz M, Gauthier G, Khan B, Abadie R, Dombrowski K, et al. Rural and urban injection drug use in Puerto Rico: network implications for human immunodeficiency virus and hepatitis C virus infection. J Ethn Subst Abuse 2018;17(2):199-222. [doi: 10.1080/15332640.2017.1326864] [Medline: 28665196]

32. Gjerde H, Øiestad E, Christophersen A. Norsk Epidemiologi. Using Biological Samples in Epidemiological Research on Drugs of Abuse URL: https://www.ntnu.no/ojs/index.php/norepid/article/view/1420 [accessed 2019-05-29] [WebCite Cache ID 78jsmObjJ]

33. Harrison L. The validity of self-reported drug use in survey research: an overview and critique of research methods. NIDA Res Monogr 1997;167:17-36. [Medline: 9243555]

34. Abdul-Quader AS, Heckathorn DD, McKnight C, Bramson H, Nemeth C, Sabin K, et al. Effectiveness of respondent-driven sampling for recruiting drug users in New York City: findings from a pilot study. J Urban Health 2006 May;83(3):459-476 [FREE Full text] [doi: 10.1007/s11524-006-9052-7] [Medline: 16739048]

35. Booth RE, Watters JK, Chitwood DD. HIV risk-related sex behaviors among injection drug users, crack smokers, and injection drug users who smoke crack. Am J Public Health 1993 Aug;83(8):1144-1148. [Medline: 8342724]

36. Dowling-Guyer S, Johnson M, Fisher D, Needle R, Watters J, Andersen M, et al. Reliability of drug users' self-reported HIV risk behaviors and validity of self-reported recent drug use. Assessment 2016 Jul 26;1(4):383-392. [doi: 10.1177/107319119400100407]

37. Fendrich M, Johnson TP, Wislar JS, Hubbell A, Spiehler V. The utility of drug testing in epidemiological research: results from a general population survey. Addiction 2004 Feb;99(2):197-208. [Medline: 14756712]

38. Brener ND, Billy JO, Grady WR. Assessment of factors affecting the validity of self-reported health-risk behavior among adolescents: evidence from the scientific literature. J Adolesc Health 2003 Dec;33(6):436-457. [Medline: 14642706]

39. Rudolph AE, Crawford ND, Latkin C, Heimer R, Benjamin EO, Jones KC, et al. Subpopulations of illicit drug users reached by targeted street outreach and respondent-driven sampling strategies: implications for research and public health practice. Ann Epidemiol 2011 Apr;21(4):280-289 [FREE Full text] [doi: 10.1016/j.annepidem.2010.11.007] [Medline: 21376275]

40. Hagan H, Perlman DC, des Jarlais DC. Sexual risk and HIV infection among drug users in New York City: a pilot study. Subst Use Misuse 2011;46(2-3):201-207 [FREE Full text] [doi: 10.3109/10826084.2011.521470] [Medline: 21303240]

41. Daniulaityte R, Falck R, Li L, Nahhas RW, Carlson RG. Respondent-driven sampling to recruit young adult non-medical users of pharmaceutical opioids: problems and solutions. Drug Alcohol Depend 2012 Feb 1;121(1-2):23-29 [FREE Full text] [doi: 10.1016/j.drugalcdep.2011.08.005] [Medline: 21885213]

42. Jenness SM, Hagan H, Liu K, Wendel T, Murrill CS. Continuing HIV risk in New York City injection drug users: the association of syringe source and syringe sharing. Subst Use Misuse 2011;46(2-3):192-200 [FREE Full text] [doi: 10.3109/10826084.2011.521467] [Medline: 21303239]

43. Qualtrics. URL: http://qualtrics.com[WebCite Cache ID 72cBHUVmv]

44. SurveyGizmo. URL: https://www.surveygizmo.com/ [accessed 2018-11-15] [WebCite Cache ID 73xF1JdHO]

45. REDCap. URL: https://projectredcap.org/ [accessed 2018-11-24] [WebCite Cache ID 749mbbuCP]

46. ICANN. IP Addresses Beginners Guide URL: https://tinyurl.com/y5t85aa6 [WebCite Cache ID 72cAunLnS]

47. Balakrishnan M, Mohomed I, Ramasubramanian V. Where's that phone?: geolocating IP addresses on 3G networks. In: Proceedings of the 9th ACM SIGCOMM conference on Internet measurement. 2009 Presented at: IMC'09; November 4-6, 2009; Mountain View, CA p. 294-300. [doi: 10.1145/1644893.1644928]

48. Zhang L. A retrospective view of network address translation. IEEE Network 2008 Sep;22(5):8-12. [doi: 10.1109/MNET.2008.4626226]

49. Ballard AM, Cardwell T, Young AM. Fraud detection protocol for web-based research among men who have sex with men: development and descriptive evaluation. JMIR Public Health Surveill 2019 Feb 4;5(1):e12344. [doi: 10.2196/12344]

50. Lansky A, Abdul-Quader AS, Cribbin M, Hall T, Finlayson TJ, Garfein RS, et al. Developing an HIV behavioral surveillance system for injecting drug users: the National HIV Behavioral Surveillance System. Public Health Rep 2007;122(Suppl 1):48-55 [FREE Full text] [doi: 10.1177/00333549071220S108] [Medline: 17354527]

51. Green T, Griffel C, Dailey T. How did you know you got the right pill? Prescription opioid identification and measurement error in the abuse deterrent formulation era. Addiction Sci Clin Pract 2015;10(Suppl 1):A16 [FREE Full text]

52. Zibbell JE, Iqbal K, Patel RC, Suryaprasad A, Sanders KJ, Moore-Moravian L, Centers for Disease Control and Prevention (CDC). Increases in hepatitis $\mathrm{C}$ virus infection related to injection drug use among persons aged $\leq 30$ years - Kentucky, Tennessee, Virginia, and West Virginia, 2006-2012. MMWR Morb Mortal Wkly Rep 2015 May 8;64(17):453-458 [FREE Full text] [Medline: 25950251]

53. WordPress. URL: http://wordpress.com[WebCite Cache ID 73xFDRjIR]

54. Home Health Testing. URL: https://www.homehealthtesting.com/13-panel-drug-test.html [accessed 2018-11-15] [WebCite Cache ID 73xFR7cTb] 
55. Cooper HL, Crawford ND, Haardörfer R, Prood N, Jones-Harrell C, Ibragimov U, et al. On point? Using web-based pin-drop maps to capture activity spaces among young adults who use drugs in rural areas. JMIR Public Health Surveill 2019. [doi: 10.2196/13593]

56. Meagher RJ, Kousvelari E. Mobile oral heath technologies based on saliva. Oral Dis 2018 Mar;24(1-2):194-197. [doi: 10.1111/odi.12775] [Medline: 29480598]

57. Vashist SK, Schneider EM, Luong JHT. Commercial smartphone-based devices and smart applications for personalized healthcare monitoring and management. Diagnostics (Basel) 2014 Aug 18;4(3):104-128 [FREE Full text] [doi: 10.3390/diagnostics4030104] [Medline: 26852680]

58. Ra M, Muhammad MS, Lim C, Han S, Jung C, Kim W. Smartphone-based point-of-care urinalysis under variable illumination. IEEE J Transl Eng Health Med 2018;6:2800111 [FREE Full text] [doi: 10.1109/JTEHM.2017.2765631] [Medline: 29333352]

59. Geocaching. URL: https://www.geocaching.com/play [accessed 2018-11-15] [WebCite Cache ID 73xI7EdsR]

60. GeoLocation O. LocationSmart. 2016. Location-as-a-Service: How Mobile, iGame and Lottery Markets Can Advance with Layered Location Intelligence URL: https://www.locationsmart.com/cms/resources/gaming-geolocation.pdf [accessed 2018-11-24] [WebCite Cache ID 749mnPKKj]

\author{
Abbreviations \\ ARC: Appalachian Regional Commission \\ CDC: Centers for Disease Control and Prevention \\ IP: internet protocol \\ MSM: men who have sex with men \\ PI: principal investigator \\ PWUD: people who use drugs \\ SAMHSA: Substance Abuse and Mental Health Services Administration \\ UDT: Urine Drug Testing
}

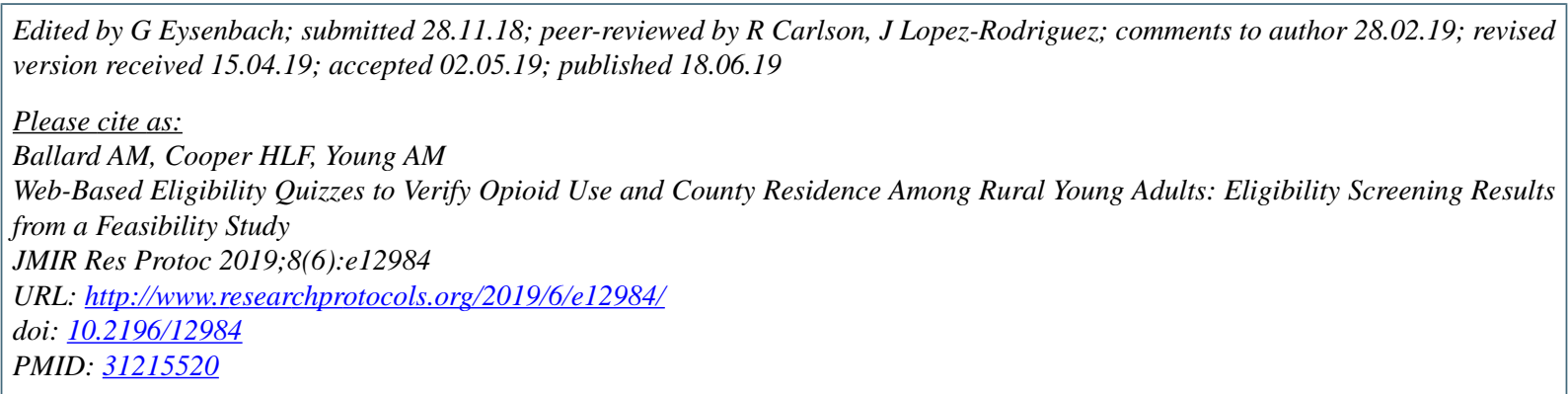

(C)April M Ballard, Hannah LF Cooper, April M Young. Originally published in JMIR Research Protocols (http://www.researchprotocols.org), 18.06.2019. This is an open-access article distributed under the terms of the Creative Commons Attribution License (https://creativecommons.org/licenses/by/4.0/), which permits unrestricted use, distribution, and reproduction in any medium, provided the original work, first published in JMIR Research Protocols, is properly cited. The complete bibliographic information, a link to the original publication on http://www.researchprotocols.org, as well as this copyright and license information must be included. 